\title{
Conversational Gambits used by the English Education Program Students of Graduate Program of State University of Padang in Classroom Discussion
}

\author{
Desti Ariani \\ Polytechnic of Raflesia-Rejang Lebong \\ arin_desti@yahoo.co.id
}

\begin{abstract}
Communicating and interacting in English in classroom discussion remains not easy for some students. In the process of discussion, students often have problems in constructing the language, in producing the language coherently and fluently, and in organizing interaction among participants. This research is a descriptive research which aims at describing conversational gambits used by the English Education Program students of Graduate Program of Padang State University in organizing their utterances and interaction in classroom discussion. Purposeful sampling was used to choose 5 classroom discussions and 13 students who actively gave verbal contribution through the using of conversational gambits. The instruments used in this research were observation, field note, and also interview. The finding showed that the type of conversational gambits frequently used by the students in classroom discussion was linking gambits. The gambits used were frequently functioned as communication control. The research also revealed that the students tended to utter certain conversational gambits; "okay" and "I think" more frequently than others which was caused mainly by their habit in using those gambits in their daily communication.
\end{abstract}

Keywords: Conversation, Gambits, Classroom Discussion

\section{INTRODUCTION}


The ability to communicate English in oral form is the primary goal that the students are eager to achieve in English Foreign Language class. Such ability requires the students to be able to structure the language correctly based on the grammar and to use the language appropriately based on the situation where the communication takes place. Thus, to obtain the ability, students are supposed to be actively involved in the activities demanding them to communicate in English. One of those activities which is often conducted to facilitate and to support the students to speak English in foreign language class is classroom discussion.

Classroom discussion offers the students a great opportunity to communicate English interactively through the use of verbal language by sharing ideas on certain given topic. However, communicating and producing ideas in English which is not the students' mother tongue is sometimes problematic and leads the students to be passive. As Gall and Gillet (2001:98) states that students do not dare to participate actively in discussion since they feel unable to use the language and afraid to make wrong contribution. In addition, Enciso (2012:10) proposes that the students' inability to participate in discussion is resulted from their poor skills in using spoken discourse to take and grasp the turn, to negotiate, to reach agreements, and to share opinion.

A preliminary observation on a classroom discussion conducted by a class consisted of 26 students of the first semester of English Education Program of Graduate Program of State University of Padang portrayed some problems that the students were dealing with. First, they had problem in constructing the language since they were lack of vocabulary. It can be seen in the situation when the students attempted to get involved in discussion, they often took a long pause while thinking the appropriate words to be uttered. Besides, they also used their mother tongue when they were unable to find the appropriate English words.

Second, the students were unable to produce the language coherently and fluently which can be seen from the situation in which the students used too many hesitation (such as: errr, mmm, aaa) but 
utilized limited number of linking words or connector. As the result, their speaking sounds far from native like.

The last problem concerned with the problem in organizing students' utterance (such as, how to explain and give information, how to nominate or change a topic, etc) and interaction (such as, how to signal turns, how to interrupt in a polite way or how to assure that others pay attention and listened while they were speaking) in the discussion. One of the conditions showing the problem above was when more than one student spoke at the same time simultaneously. This condition implied that those students were failed to signal their turn in getting involved in the discussion. Another condition was when a presenter kept speaking and giving explanation while the others were busy on their own activity which implied that the speaker was unable to control the communication and ignored to assure the audience paid attention and listened to his explanation. These conditions are actually resulted from the inability in using conversational signal, namely gambits.

Gambits as the conversational signal used to organize utterance and interaction are often employed in classroom discussion. They refer to the words, phrases, or sentences that are utilized by a speaker to help him convey what he wants to say, such as to introduce a topic of conversation, to link his idea to the previous one, or to respond a certain utterance given by another (Keller and Warner, 2002:4).

In discussion, there are some gambits which are frequently used by the students, such as In my point of view...." to express opinion, "Sorry for interrupting..." to interrupt someone's speaking, or "I would like to say something on that" to signal that the students wish to take speaking turn. However, the gambits are not limited to such expressions above. Gambits may also appear in a simple word such as "First", "Second" to indicate the students' intention to list something, or "Okay", "Right" to show interest.

The use of conversational gambits in classroom discussion seems to bring benefits for both speakers and listeners. For the speakers, gambits may function in several ways. First, the gambits are served as 
connectors or markers which help them to organize their utterances in a coherent discourse. Second, those gambits can be a strategy for maintaining the smooth flow of the communication by signaling their turn. Finally, they also can be pause filler which provides time for the speakers to repair and reconstruct their language while speaking (Keller, as cited in Taylor, 2002:172). Meanwhile, for the listeners, the existence of the gambits in the speakers' utterance is beneficial in helping them to figure out what actually the speaker is about to say, so they do not get lost and not misunderstand.

Based on the preliminary observation, the students also used conversational gambits to organize their utterances and interaction during discussion. However, they tended to use limited variation of conversational gambits. In this case, the students tended to use the same gambit to express certain purpose from many other alternatives. For instance in giving opinion, the students frequently used gambit " $I$ think" rather than "In my opinion", "From my point of view," or "In my understanding". Further, the students were lack of understanding on the factors necessary for choosing and using conversational gambits which are appropriate to the native norm. For example, the students chose using "I will try to present......" instead of "I would like to present....." which is more appropriate and commonly used to introduce a topic in a formal situation. Finally, the students did not have a clear understanding on the function of the gambits. It can be seen from inappropriate use of gambits in their speaking, such as too many gambits were employed as fillers in one occasion.

Due to the important role of conversational gambits in classroom discussion and the problems faced by the students above, the writer intends to do further research on this gambits phenomenon. The research then focuses on investigating the types of gambits frequently used, the functions of those gambits, and the students' reasons in using certain gambits more frequently than others in classroom discussion. Hopefully, the result of the research gives a contribution in English language learning from a clear picture on the use of gambits acquired. Both lecturers and students may get better understanding on what gambits are and how important they are in verbal communication. 
Lecturers may evaluate the techniques or material used to teach speaking, specifically gambits, which in fact are rarely taught in the classroom. In addition, students will be able to use more variations of gambits which are appropriate to the target language norms that further are beneficial for enhancing their communicative skills.

\section{THEORITICAL FRAMEWORK \\ Defining Conversational Gambits}

According to House (as cited in Muler, 2005: 23), gambit refers to the linguistic features frequently used in oral interaction that function as markers helping a speaker to organize his utterance into a good discourse Meanwhile, Richard and Schmidt (2010: 239) define gambit, which is known as conversational routine as well, as a word or phrase used to signal the participants' turn and their contribution in a conversation whether to add new information, to develop the idea given by the previous participant, to express opinion, etc. Not so different, Keller (as cited in Nikhmer, 2013: 23) states that "gambits are certain conversational signal used to introduce level shifts within the conversation or to prepare listeners for the next turn in the logical argument".

The three statements above have underlined the meaning of gambits seen from discourse perspective in which the gambits are recognized as the device that may guide the speaker and listener for having comprehension on the communication through discourse processing by semantically framing certain information or by facilitating the speakers and listeners' turn taking.

In different perspective, Yorio (1980: 437) proposes that gambits are the formulaic expressions which are used not only as the strategy to organize written or oral text but also as the strategy for conversational interaction. Yorio's idea emerges the importance of gambits in relation to the interactional function of a conversation which focuses on establishing and maintaining social relationship.

\section{Types of Conversational Gambits}


Edmonson and House (as cited in Jantscher, 2007: 206) differentiates the types of gambits into three; up-takers, clarifiers, and appealers. Up-takers refer to the speaker's acknowledgement of the preceding utterances made by the interlocutor which aim at prefacing a speaker's move (yeah, yes, I see, right, okay, hmm, ah, uh) and expressing speaker's attitude or emotion toward what he has just heard, such as expressing interest, surprise, or disbelief (really, great, terrific, good, oh dear, not again). Clarifiers refer to the utterances that are uttered now which aim at establishing, increasing, and restoring the relationship between the participants of the conversation in which a speaker intends to say something which is not welcoming to the listeners (you see, you know) and also emphasizing a point that the speaker makes (I'll tell you what, this is what I'm getting at). And the last, appealers refer to the utterances of the speaker which aim at inviting the listeners to take turn in giving agreement or acknowledgment (question tags, okay, right).

Another idea on the types of gambits is suggested by Keller and Warner (2002: 4). They prefer the common terms which are easier to be understood together with detail subtypes of the gambit as follow:

\section{Opening gambits}

Opening gambits occur when a speaker intends to start a conversation or to introduce new idea during the conversation. For example: someone may say "Excuse me, please" to attract someone's attention in order to open a conversation. He then may say "in my view" to introduce something more serious.

\section{Linking gambits}

Linking gambits are those used to link the speaker's idea to the previous ideas delivered by himself or another. By using linking gambits, the speaker can move from one idea to the next in a good logical order. Therefore, it will be easier for the listeners to understand what the speaker says. At the same time, those gambits will help the listeners to be more prepared to reply the speaker's utterances. For example: gambit "in addition......" indicates that the speaker tries to add information on his previous utterance, or the gambit "what I'm trying to say is....." may be used to correct his words.

\section{Responding gambits}


A communication can be said successful when a listener knows how to respond what the speaker says appropriately. Thus, responding gambits aim at helping the speaker to respond the other's utterance, usually for stating agreement/disagreement, showing surprise, disbelief, polite interest, or checking someone understanding. Someone may say "you must be joking!" with a higher tone to show that he is strongly disagreed with what another has just said.

The two ideas on the types of gambit proposed by Edmonson and House and also Keller and Warner above actually have something in common. They are used to regulate the discourse of speech among the participants of a conversation by signaling the turn and regulate the interaction by giving certain respond. Although Edmonson and House and Keller and Warner use the different terms for the types of gambit, some of those terms actually refer to the same thing. The up-takers and clarifiers proposed by Edmonson and House somehow have the same meaning to the responding and linking gambits proposed by Keller and Warner.

\section{Functions of Conversational Gambits}

Keller (as cited in Taylor, 2002: 172 and in Nikhmer, 2013: 228) proposes that gambits may serve one or more of the four functions; as semantic introducers, signaling the participants' social context, signaling a person's state of consciousness, and as communication control. The first function of gambits is as semantic introducer. Gambits in this case provide the general frame of the topic that the speaker wishes to convey in his utterance whether to frame his intention in giving opinion, suggesting, interrupting, adding thing, and so on. The second function of gambits is as the signal of the participant's social context. Thus, gambits expressions can be used to signal the participant's turn in the interaction whether taking turn, holding turn, relinquishing turn or abandoning turn. By signaling their turn, a speaker can keep the flow of the interaction and avoid the problems such as overlapping or long pause. The third function of gambits is as the signal 
of a person's state of consciousness. Gambits are used to indicate someone's readiness to receive or to provide new information and to suggest that some knowledge or concern is being shared. And the last function is as communication control. In this case, gambits are used as pause fillers to gain the time while speaking, and to assure that the communication channel is opened.

In addition, Dornyei and Scott (1997: 190) introduce gambits in their theory on communication strategies. They identify gambits as one of the strategies called as the stalling and time-gaining strategies which aim at helping the speakers to overcome the problems and maintaining the communication process. Dornyei and Scott's idea stating that gambits serve the function to fill the pause and to assure that the communication channel is opened is in line with the communication control function proposed by Keller. As fillers, gambits may help a speaker dealing with his insufficient vocabulary and grammar by providing him the opportunity to repair and reconstruct his language while speaking. And at the same time, long pause or even silence can be avoided. Some gambits commonly used for this purposes are "okay, well, you know, you see, etc". Meanwhile, the gambits "are you with me? is that clear? etc" function at assuring that the listeners pay attention and understand on what the speaker says therefore the channel of the conversation remains open.

Meanwhile, Wray (2000) seems to compile the function of gambits proposed by Keller and Dornyei and Scott in the term of formulaic sequences. According to Wray, gambits or formulaic sequences have two main functions; saving effort in processing utterances and achieving socio-interactional functions. The first function is that gambits may help the speaker to achieve speedily access in processing utterances in three ways; as fillers (if you like, if the truth be told) by giving the time for the speaker to think, as turn signals (let me just say, I wanna tell you...), and as discourse markers (firstly, secondly) by framing the construction of speaker's discourse. The second function relates to the aspect on how someone should treat and should be treated in a social communication either in requesting (could you repeat that please), thanking (thank you very much), and so on. In line with Wray, Slade and Thornbury (2006) 
develop the functions of gambits in terms of conversational routines. Those functions are as fillers (I mean, sort of), discourse markers (on the other hand, by the way, in other words), and social formula (greeting, thanking, offering, etc).

\section{Factors that Influence the Choice of Gambits}

People involve in a large number of communication that requires them to use different variation of language. In language learning, the ability to use the appropriate variation of language is one of the measurements of fluency. In this case, someone is considered to be fluent in speaking a certain language when he is able to match the language used to the settings where the communication takes place, to the persons whom he talks to, and to the context in which the language is being used. Gambits, just like other language features, also have a large variation. Therefore, to choose the appropriate gambits to be used in a communication, someone should consider two important factors; situation and participants/audiences (Keller, in Coulmas, 1981: 105).

The first factor proposed by Keller in choosing the appropriate gambits is the situation. Gambits should be used based on the context and the situation of the communication. Supporting Keller's idea, Muller (2005: 105) gives the example on the difference use of two gambits commonly uttered for doing interruption; "Excuse me for interrupting" which is more appropriate to be used in formal situation and "wait a minute" which is more suitable in informal and familiar context. Another support comes from Edmonson and House (as cited in Duffon, 1995: 28) who underline the effect of using inappropriate gambits toward the speaker. Further they explain that when a speaker uses gambits inappropriately to the situation, the speaker may be regarded as uncooperative and impolite.

The second factor mentioned by Keller is participants/ audience. The social role occupied by the participants within the group and the size of the audience are two aspects necessary to be considered at this 
point. What is said by Keller as social role has been further explained by Brown (2003: 5). According to Brown, social role implies someone's position in a group, for instance as teacher or student in the classroom, as manager or employee in an office, or as parent or children in a family. Those roles may affect the language choice to be used in the communication.

Besides social role, the size of the audience also influences the choice of gambits. Keller states "several gambits are marked for use with a single listener, while with a larger audience, the unmarked form might be used." For instance, to offer a suggestion to a single audience, one might say "If I were you," while for more than one audience, one might choose the unmarked form "why not....".

\section{RESEARCH METHODOLOGY}

This research was carried out through a descriptive research. The population of the research was the first semester of English Education Program of Graduate Program of State University of Padang. There were about 63 students. The sample taken for the research was those who involved in 5 classroom discussions. They were chosen by using purposeful sampling.

There are two kinds of data collected for the research. The first one is the students' interaction consisted of the conversational gambits used in classroom discussion. The writer obtained these data by doing direct observation on several classroom discussions. And the second is the interview on the students' reasons for frequently using certain gambits. Both of the data above were collected by using video recording.

The data were analyzed by applying procedures suggested by Miles and Huberman (1994:10). First, the writer selected only useful data taken from all the data that had been collected from the observation and interview. For observation data, from 7 classroom discussions observed, the writer just chose 5 of them which provided clearer audio visual data needed for making transcription. In the same line, the writer only chose 8 from 13 interviews since they had provided enough information and the rest interviews tended to repeat the 
information got from the 8 interviews. Both of the data then were transcribed.

After making transcription, the writer organized the collected data by classifying them into the types and functions of conversational gambits. Next, the writer calculated the frequency of the conversational gambits used and correlated the frequency with the factors that influence the students to choose certain conversational gambits gotten from the interviews. Finally, the writer summed up and took final conclusion by adjusting all the data from the observation with the interview result.

\section{FINDINGS AND DISCUSSION}

\section{Type of conversational gambits frequently used by the students in classroom discussion}

From five classroom discussions observed, it is discovered that the students employed gambits about 262 times in their interaction during the process of discussion. The gambits used are included into three types; opening, linking, and responding. Among these types, linking gambits is found to be used more frequently by the students. The results of the data are presented as follow:

\section{Table.1}

The Frequency of Types of Conversational Gambits Used by the Students in Classroom Discussions.

\begin{tabular}{lll}
\hline $\begin{array}{c}\text { Types of } \\
\text { Conversational } \\
\text { Gambits }\end{array}$ & Frequency & Percentage \\
\hline Opening & 39 & $14.89 \%$ \\
Linking & 144 & $54.96 \%$ \\
Responding & 79 & $30.15 \%$ \\
Total & 262 & $100 \%$ \\
\hline
\end{tabular}


To be clearer, the frequency of the types of conversational gambits used by the students in classroom discussion can be seen from the graphic below:

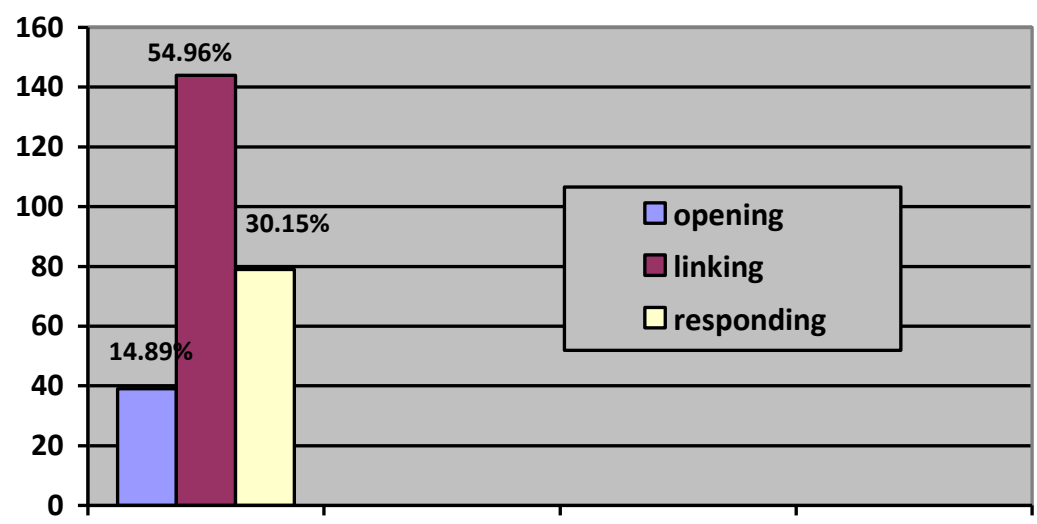

Graphic.1.

The Frequency of Types of Conversational Gambits Used by the Students in Classroom Discussions.

Linking gambits was used more frequently since the important part of the discussion itself is when the students each other shares their understanding on the topic of discussion which requires them to add information, to summarize their explanation, to emphasize an aspect, to clarify their own or others' utterances, as well as to fill the pause occurring during the sharing process. Therefore, in the practice, the students employed 6 subtypes of linking gambits served for the purposes above; adding thing, ending/summarizing, emphasizing an aspect, clarifying own word, clarifying other's words, and filler gambits. Among these subtypes, fillers were utilized much more frequently. It can be seen from the frequency of fillers which is much higher than those of other subtypes.

\section{Functions of the conversational gambits used by the students in classroom discussion}

From the data taken, it was found that the gambits employed by the students during discussion fulfill four functions; as semantic 
introducer, as the signal of the participant's social context, as the signal of a person's state of consciousness, and as communication control. However, those functions are quite different in the term of their frequency.

Table. 2

The Frequency of Functions of Conversational Gambits Used by the Students in Classroom Discussion

\begin{tabular}{|c|c|c|}
\hline $\begin{array}{cc} & \text { Functions of } \\
\text { Conversational } \\
\text { Gambits }\end{array}$ & Frequency & Percentage \\
\hline As semantic introducer & 73 & $19.16 \%$ \\
\hline $\begin{array}{l}\text { As the signal of the } \\
\text { participant's social } \\
\text { context }\end{array}$ & 119 & $31.23 \%$ \\
\hline $\begin{array}{l}\text { As the signal of a } \\
\text { person's state of } \\
\text { consciousness }\end{array}$ & 17 & $4.46 \%$ \\
\hline $\begin{array}{l}\text { As communication } \\
\text { control }\end{array}$ & 172 & $45.15 \%$ \\
\hline Total & 381 & $100 \%$ \\
\hline
\end{tabular}

To be clearer, the frequency of the functions of conversational gambits used by the students in classroom discussion can be seen from the graphic below: 


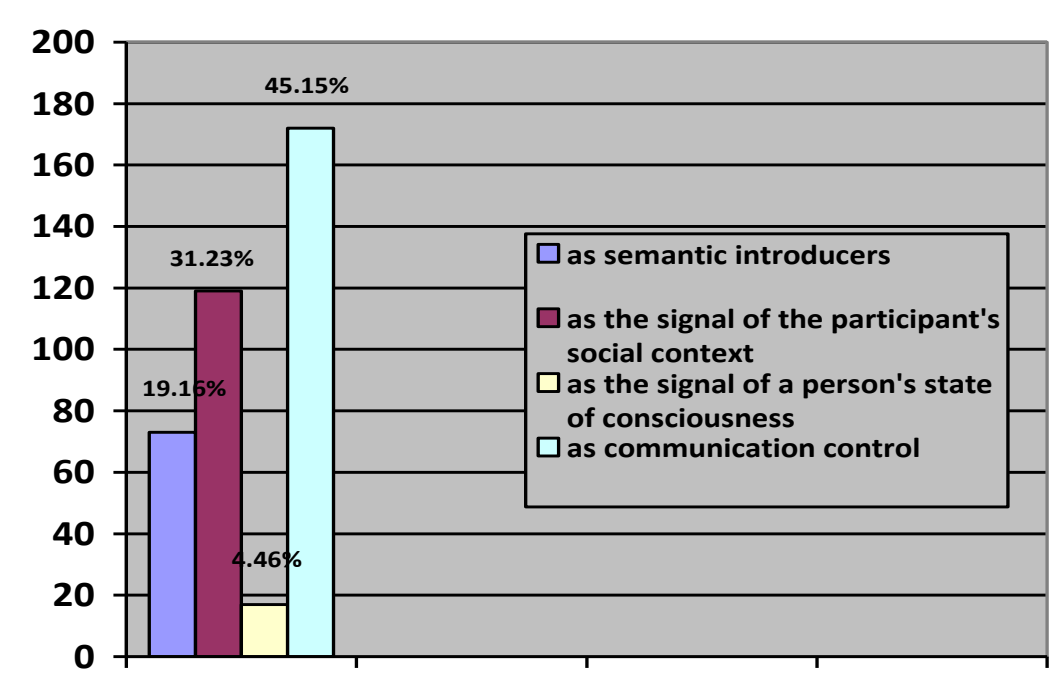

Graphic.2

The Frequency of Functions of Conversational Gambits Used by the Students in Classroom Discussions.

The first function is as semantic introducers; introducing the general frame of the students' talk. In the practice, the gambits were largely employed at the beginning of students' statements and were purposeful to prepare the listeners for the message which soon would be uttered that hence made the listeners planning an appropriate response. Gambit "It's better to..." for an instance, were used to lead the listeners' understanding that the speaker would share suggestion. The listeners then might agree, disagree or give an addition toward the suggestion offered as a response. Thus, the gambits function as semantic introducers are categorized into the gambits of giving opinion, asking for information, offering suggestion, clarifying own words, summarizing, adding thing, emphasizing an aspect, clarifying other words, expressing understanding, and agreeing/disagreeing.

The second function of gambits is as the signal of a participant's social context. Gambits were used by the students to signal their turn whether in taking, holding, or relinquishing the turn. To signal their willingness in taking the floor, the students employed gambits at the 
beginning of their utterance. On the other hand, to signal their intention to hold the turn, they used gambits in the middle of their utterance. As it is observed, the most frequent gambits used to signal this taking and holding turn are those categorized into filler gambits. This finding is supported by Thornbury and Slade (2006:56) who say that fillers mainly employed in two positions; at the beginning of the speaker's utterance to indicate his intention to take turn and in the middle of his utterance that indicates his speaking turn is not yet finished.

Viewed from their frequency, these taking and holding turn were quite frequently used by students during discussion. The reason perhaps is due to the necessity in maintaining the organization of they own utterances and the orderly of their turn transition to avoid problems, such as silence or overlapping. It can be seen from the evidence that only a few interruption were made by the student.

Different with taking and holding turn, gambits which were used to relinquish turn were employed at the end of students' utterance that hence indicates they have finished their speaking turn and would like others to take over. For this purpose, the gambits used are those categorized into the checking gambits. This relinquishing turn is dominated by moderator and the reason might be that moderator acts as person in charge in moderating the process of discussion including in arranging the students' transition in speaking. Thus, to organize the turn transition, the moderator nominates the student who will be the next speaker. This is in line to what is said by Schamatzer (as cited in Pohaker, 1998:30) that a chairman in a meeting may select next speaker and invite him to give contribution by pronouncing the name and using certain gambits expression, such as "Would you like to comment on this?" or "What are your views on that?".

The next function of gambits used by the students in the discussion is as the signal of the students' state of consciousness. The term consciousness seems to refer to students' awareness in choosing a subset of gambits to deliver their ideas in order to achieve certain effects. Some certain gambits, based on the data, were chosen by students for some purposes; to indicate their readiness in providing 
information and also to signal whether they have the same or different knowledge. Gambit "I want to give addition", for example, was selected by the students to indicate that the upcoming utterances would be addition of the previous explanation that might gain other participants' attention. Thus, the gambits used for this purpose are categories into giving opinion, offering suggestion, adding thing, clarifying own words, and agreeing/disagreeing gambits.

However, the term of consciousness shall not be generalized to all gambits used. Nikhmer (2013:233) proposes that some gambits were used unconsciously by the people since those gambits already become their personality and are habitually used in their interaction. Nikhmer's idea supports the finding of the current research that some of the gambits, such as "I think" and "Okay", were so frequently used out of the students' awareness. The interview shows that the students used these gambits just because of their habit in using them again and again in every speaking.

The last function of gambits utilized by the students in classroom discussion is as communication control. Compared to other three functions of gambits mentioned earlier, communication control takes the highest frequency which means that the gambits used by the students in classroom discussion were mostly functioned at controlling their communication. The result of observation portrays that students control their communication during the process of discussion in three ways; filling the pause, establishing and maintaining social relationship, and keeping the channel opened.

Gambits serve a communication control in the case that they were used to fill the pause appearing in the communication. According to Simensen (2010:3), gambits which are lexical items with no conventional meaning are often used to fill the pause which naturally occurs when speaker starts to breathe, to organize, and to choose the best words before conveying ideas. Simensen's statement implies that gambits might control the communication by providing the time for speakers to organize their utterances. What is said by Simensen supports the finding of the current research that the students often employed gambits to fill the pause appearing in two sequences of the 
discussion; at turn exchange and during the students' speaking turn. Thus, the gambits used for this purpose are those categorized into filler gambits.

At turn exchanges, students frequently employed these gambits at the beginning of their utterance. The result of the interview discloses that filler gambits, at this sequence, were used as the starting point of students speaking which were purposeful to provide extra time for them to prepare the words to be uttered as well as to gain other students' attention. During the students' speaking turn, the gambits were likely used to gain time needed to choose the appropriate words and to reconstruct their language. In short, gambits served the communication control function since they helped students to control and maintain their speaking turn and to prevent long pause which might break down the communication during the discussion.

Establishing and maintaining social relationship among participants of discussion through the use of gambits remains to be another way to control communication. Wray (2000:477), who introduced this function under the topic of formulaic sequence, states that the use of formulaic sequence, such as gambits, emphasizes on the effects of the gambits used on the hearers. Further, he explains that the use of gambits in social interaction is purposeful to manipulate others and to stratify their emotional needs whether by requesting, apologizing, or thanking. Relevant to this theory, the current research reveals that gambits were largely used as socio-interactional mentioned above. Thus, the gambits used for this purpose are those which fall into thanking gambits.

From the data, thanking gambits were utilized by the students to represent their respect and appreciation for getting turn to speak, for getting information, and for getting attention that the other participants gave during discussion. Related to Wray's theory, showing respect and appreciation will probably give a positive effect on creating a comfortable atmosphere among participants of discussion. As the result, students might be able to establish and maintain their social relationship. Besides, the fact that in Indonesian culture expressing 
thanking is considered polite perhaps becomes another reason for the students to use thanking gambits so frequently.

Finally, keeping the channel opened has been found to be the last way in controlling the interaction during discussion. The gambits used for this purpose are those categorized into checking and expressing understanding gambits. As it is observed, checking gambits were employed by the students for two reasons. The first is to assure sure they have the same idea on the topic of the question before giving an answer. The second is to assure that the explanation conveyed was understood by the listeners. Expressing understanding gambits, on the other hand, were utilized as the response to the checking gambits; to express their understanding. By checking and expressing understanding, students might be on the same track and might not get lost on the topic of discussion. Therefore, they could maintain the continuity of their ongoing talk that further would sustain the continuity of the process of discussion itself.

\section{The reasons of the students in frequently using certain conversational gambits in classroom discussion}

Another remarkable point of the finding is that the students tended to use certain conversational gambits in classroom discussion. Two gambits are noted to be the most frequent used by the students. They are "Okay" which occurred 86 times and "I think" which occurred 16 times. Based on the result of the interview, students used those two gambits more frequently than other gambits served for the same purposes for some reasons.

The first reason relates to the students' habit. According to the students, they tend to use a certain gambit since they are accustomed to using those gambits in their daily communication. This reason is supported by Nikhmer (2013:233) who argues that some gambits are routinized since they are used habitually by the people.

The second reason is because those gambits are considered simpler to be used. The term "simpler" in this research was annotated by the students to word by word translation of Indonesian. Since it is 
not time-consuming, word by word translation seems to be used by the students to compensate the limited time they have in each turn of speaking.

The last reason is because in students' point of view, those two gambits are more common used in formal or informal situation. In accordance with the factors that influence the using of certain gambits proposed by Keller (in Coulmas, 1981:105), this last reason implies that the students also consider the situation where the communication takes place in using certain variation of gambits.

\section{CONCLUSION}

Based on the result of the findings, it can be concluded that the type of conversational gambits frequently used by the students in classroom discussion is linking gambits. From some subtypes of linking gambits, fillers are the most frequent employed by the students to fill the pause and to obtain time to think. Most of the conversational gambits which were employed by the students in classroom discussion function as communication control. However, they may also function as semantic introducer, as a signal of participant's social context, and also as a signal of a person's state of consciousness with less frequency. During the discussion, students frequently used certain gambits for some reasons. First, the students are accustomed to using those gambits in their daily communication. Second, in students' point of view, those gambits are simpler since they are translated directly from Indonesian. Third, those gambits are considered appropriate to be used in formal or informal situation.

\section{REFERENCES}

Chalak, Azizeh and Norouzi, Zahra. 2014. A Contrastive Analysis of English and Persian Native Speakers' Use of Gambits. IJRELT, Vol. 1. No. 3, pp: 61-70. 
Coulmas, Florian. 1981. Rasmus Rask Studies in Pragmatic Linguistics. Vol 2: Conversational Routine. Netherlands: Mouton Publishers.

Enciso, Olga Lucia Uribe. 2012. Helping Business English Learners Improve Discussion Skills. Colombian Applied Linguistic Journal. Vol. 14, No. 2, pp: 1-76.

Gall, M. Damien and Gillet, Maxwel. 2001. The Discussion Method in Classroom Teaching. treeturtle.com/thediscussionmethod.pdf. Retrieved on March 19th, 2014.

Keller, E. 1979. Gambits: Conversational Strategy Signals. Journal of Pragmatics. Republished in Coulmas (1981) Rasmus Rask Studies in Pragmatic Linguistics. Vol 2: Conversational Routine. Netherlands: Mouton Publisher.

Keller, E and Wanner S. 2002. Conversation Gambits. Real English Conversation Practices. $2^{\text {nd }}$ Ed. Boston: Language Teaching Publication.

Miles, M.B. and Huberman, A.M. 1994. Qualitative Data Analysis. $2^{\text {nd }}$ Ed. SAGE Publications. London: International Educational and Professional Publisher.

Nikhmer, Amir. 2013. Gambits in a New Light. International Journal of Applied Linguistics \& English Literature. Vol. 2, No. 4.

Pöhaker, K. 1998. Turn-taking and gambits in intercultural Communication. Instituf für Anglistik. http://archive.ecml.at/documents/.../pdescPenzE2001.pdf. Retrieved on April 1st, 2014.

Simensen, A.M. 2010. Fluency: an aim in teaching and a criterion in assessment. Acta Didactica Norge. Vol. 4 Nr.1 Art.2, pp: 1-13. 
Taslim, Fadila. 2014. "Communication Strategies in Question and Answer in Class Discussion of Second Semester Students at the English Education Program of Graduate Program of State University of Padang". Unpublished Thesis. State University of Padang: English Education Program.

Taylor, Gregory. 2002. Teaching Gambits: The Effect of Instruction and Task Variation on the Use of Conversation Strategies by Intermediate Spanish Students. Foreign Language Annals. Vol. 35, No. 2.

Thonbury, Scott and Slade, Diana. 2006. Conversation: From Description to Pedagogy. Cambridge University Press.

Wray, A. 2000. Formulaic Sequences in Second Language Teaching: Principle and Practice. In Applied Linguistic, 21/4, pp: 463-489. 
158 | ENGLISH FRANCA, Vol. 2, No. 2, 2018 